\title{
Ketamine for the treatment of mental health and substance use disorders: comprehensive systematic review - CORRIGENDUM
}

Zach Walsh, Ozden Merve Mollaahmetoglu, Joseph Rootman, Shannon Golsof, Johanna Keeler, Beth Marsh, David J. Nutt and Celia J. A. Morgan

\section{Keywords}

Alcohol disorders; anxiety disorders; depressive disorders; mental health disorders; ketamine.

\section{Copyright and usage}

(C) The Author(s), 2022. Published by Cambridge University Press on behalf of the Royal College of Psychiatrists. This is an Open Access article, distributed under the terms of the Creative Commons Attribution licence (https://creativecommons.org/licenses/by/4.0/), which permits unrestricted re-use, distribution, and reproduction in any medium, provided the original work is properly cited.

https://doi.org/10.1192/bjo.2021.1061, Published online by Cambridge University Press, 23 December 2021.
In the original publication, ${ }^{1}$ an error was made in the introduction. In the first sentence of the Background section, 'agonist' should have been 'antagonist'. This has now been corrected in both the online PDF and HTML versions of this article. The authors apologise for this error.

\section{Reference}

1 Walsh Z, Mollaahmetoglu OM, Rootman J, Golsof S, Keeler J, Marsh B, et al. Ketamine for the treatment of mental health and substance use disorders: comprehensive systematic review. BJPsych Open, 8(1), e19. https://doi.org/ 10.1192/bjo.2021.1061.

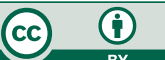

